\section{How prions kill brain cells}

Brain-wasting proteins called prions kill neurons by shortening the dendritic spines that the cells use to transmit signals to each other.

Prions are infectious and cause neurodegenerative diseases such as scrapie in animals and CreutzfeldtJakob disease in humans. To learn how they kill brain cells, David Harris at Boston University in Massachusetts and his co-workers exposed cultured mouse neurons to the prion that causes scrapie in mice. They found that the neurons' dendritic spines retracted within 24 hours, before the cells died. This occurred only in neurons that made the normal, noninfectious form of the prion protein, which suggests that the disease-associated prion might bind to the normal one to trigger dendritic loss.

This method could be used to test potential drugs against prion diseases, the authors say. PLoS Pathog. 12, e1005623 (2016)

\section{ARCHAEOLOGY}

\section{Ancient beer recipe from China}

A 5,000-year-old brewery in China used what was then an unusual ingredient - barley.

A team led by Jiajing Wang at Stanford University in California analysed starch grains from pottery resembling brewing vessels (reconstructions pictured), which were discovered at the Mijiaya site in northern China about a decade ago. The vessels contained a mixture of millet, tubers, a tropical grass known as Job's tears, and barley. Some grains were swollen and deformed as though they had been mashed, a process that uses hot water to extract sugars. Chemical analysis of residues on the pottery revealed calcium oxalate, a common by-product of beer making.

Barley was domesticated in Western Eurasia around 10,000 years ago, but it did not become a major crop in China until around 2,200 years ago. The Mijiaya brewers may have seen barley as an exotic treat, the authors suggest.

Proc. Natl Acad. Sci. USA http://doi.org/bhwm (2016)

\section{ANIMAL BEHAVIOUR}

\section{Onlookers boost mouse chatter}

Male mice communicate more in front of an audience than when they are alone.

Mice live in large social groups and communicate using ultrasonic frequencies. To learn how this social environment influences their vocalizations, Roian Egnor of the Howard Hughes Medical Institute's Janelia Research Campus in Ashburn, Virginia, and her colleagues exposed male mice in the lab to a female odour. They then compared vocal responses from animals that were alone to those that were in the presence of another male. Males that had an audience produced vocalizations that were longer and more complex than those from solo males.

The male mice could be communicating to other males to compete for mates, the authors suggest. J. Exp. Biol. 219 1437-1448 (2016)

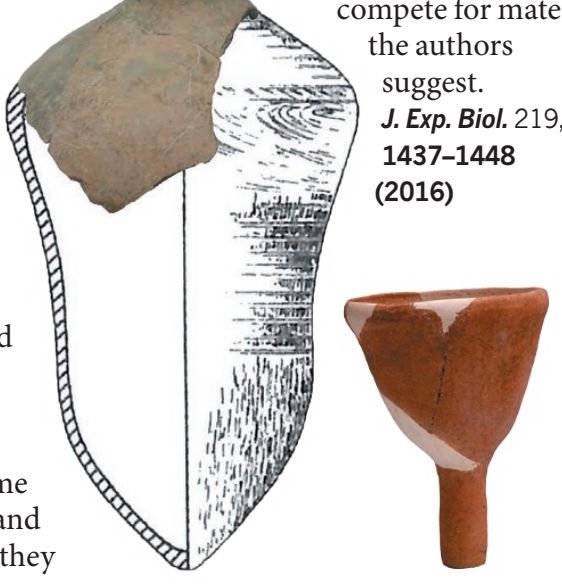

\section{ZOOLOGY}

\section{Squid may reach epic sizes}

Giant squid could measure up to 20 metres in length.

Fewer than 500 of the mysterious invertebrates (genus Architeuthis) have ever been measured. To calculate their maximum possible size, Charles Paxton of the University of St Andrews, UK, compiled recorded measurements of giant squid, and established relationships between measurements such as the length of the whole body, the mantle and the beak. These relationships, and the variation between observed squid lengths and beak sizes, suggest that the animals could plausibly be 20 metres long.

Paxton says that some giant squid may grow too large to be eaten by some of their predators, such as female sperm whales.

J. Zool. http://doi.org/bhwq (2016)

\section{GENOMICS \\ Genetic clues to more rubber}

The genome of the rubber tree has revealed a group of genes that may drive the plant's unique ability to produce vast amounts of rubber.

Scientists had previously released a draft sequence, but Chaorong Tang at the Chinese Academy of Tropical Agricultural Sciences in Danzhou and his colleagues now report a more complete genome sequence for the plant (Hevea brasiliensis; pictured). Four members of the $R E F / S R P P$ gene family, which are thought to be involved in rubber synthesis, were among the most highly expressed genes in latex, the white fluid from which natural rubber is obtained. The researchers also identified more than 500 genes that respond to ethylene, a plant hormone known to stimulate rubber production.

These findings could help to guide efforts to breed higher-yield versions of the

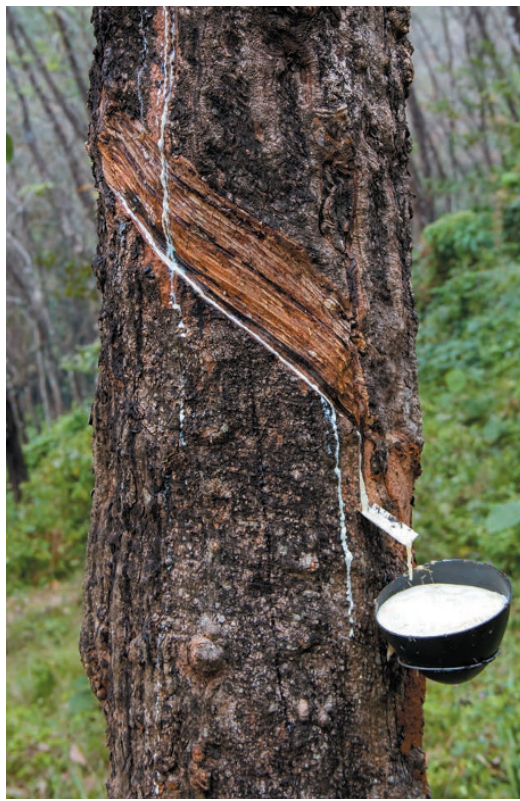

commercially important plant, the authors say.

Nature Plants http://doi.org/ bhwn (2016)

\section{MATERIALS}

\section{Light heals defects in solar-cell film}

Intense light shining on a material used in experimental solar cells can improve its performance.

Perovskite films promise to increase the efficiency of solar cells, but imperfections in the material, called traps, limit further gains. A team led by Samuel Stranks of the Massachusetts Institute of Technology in Cambridge found that intense light reduces the density of the traps by tenfold, boosting performance. Chemical imaging revealed that iodine ions migrated away from the illuminated areas, and the authors suggest that this effectively swept the traps away.

The effect fades over time, but the authors hope to devise a method with longerlasting effects for commercial applications.

Nature Commun. 7, 11683 (2016)

\section{$\rightarrow$ NATURE.COM}

For the latest research published by Naturevisit:

www.nature.com/latestresearch 